Louisiana State University

LSU Digital Commons

Faculty Publications

Department of Biological Sciences

$11-29-2015$

\title{
Corticosteroids in pediatric ARDS: all cards on the table
}

Andreas Schwingshackl

David Geffen School of Medicine at UCLA

Gianfranco Umberto Meduri

David Geffen School of Medicine at UCLA

Dai Kimura

David Geffen School of Medicine at UCLA

Stephania A. Cormier

David Geffen School of Medicine at UCLA

Kanwaljeet J.S. Anand

David Geffen School of Medicine at UCLA

Follow this and additional works at: https://digitalcommons.Isu.edu/biosci_pubs

\section{Recommended Citation}

Schwingshackl, A., Meduri, G., Kimura, D., Cormier, S., \& Anand, K. (2015). Corticosteroids in pediatric ARDS: all cards on the table. Intensive Care Medicine, 41 (11), 2036-2037. https://doi.org/10.1007/ s00134-015-4027-3

This Letter to the Editor is brought to you for free and open access by the Department of Biological Sciences at LSU Digital Commons. It has been accepted for inclusion in Faculty Publications by an authorized administrator of LSU Digital Commons. For more information, please contact ir@lsu.edu. 


\section{UCLA}

\section{UCLA Previously Published Works}

Title

Corticosteroids in pediatric ARDS: all cards on the table

\section{Permalink}

https://escholarship.org/uc/item/0r18h0s6

\section{Journal}

Intensive Care Medicine, 41(11)

\section{ISSN}

0342-4642

\section{Authors}

Schwingshackl, A

Meduri, GU

Kimura, D

et al.

\section{Publication Date}

2015-11-29

\section{DOI}

10.1007/s00134-015-4027-3

Peer reviewed 
Andreas Schwingshackl 1 Gianfranco Umberto Meduri Dai Kimura

Stephania A. Cormier Kanwaljeet J. S. Anand

\section{Corticosteroids in pediatric ARDS: all cards on the table}

\author{
Accepted: 8 August 2015
}

(C) Springer-Verlag Berlin Heidelberg and ESICM 2015

Dear Editor,

Hardly any topic in modern critical care medicine remains as controversial as steroid administration in acute respiratory distress syndrome (ARDS), despite multiple adult randomized controlled trials (RCTs) and recent pediatric data. The article by Yehya et al. [1] and the editorial commentary by Peters et al. [2] are vital, since few, if any, therapeutic approaches are simultaneously associated with such profound potential benefits and risks as steroid therapy in critically ill patients.

Marked contradiction, however, exists between the Yehya et al. data and the findings of well-designed and protocol-driven RCTs in adult ARDS patients. These studies consistently reported significant improvements in markers of systemic inflammation, ventilator-free days, ICU-free days, no changes or actually improved survival, and either no increase or decreases in infection rate $[3,4]$. The findings of Yehya et al. cannot be interpreted because the specific indications for corticosteroid use were not reported. To imply that any type of steroid, at any concentration, and used for more than $24 \mathrm{~h}$ represents a protocol-driven treatment for pediatric ARDS (PARDS) is simply not justifiable.

Further, grouping short-term (less than $24 \mathrm{~h}$ ) and non-corticosteroid exposed patients together is an improper control for evaluating steroid therapy. Corticosteroids can exert important, non-genomic effects within minutes, including decreased cell adhesion, phosphokinase activation, MCP- 1 and $\mathrm{H}_{2} \mathrm{O}_{2}$ release, $\mathrm{CD} 63$ translocation, TNF- $\alpha$ and IL-6 expression. Possible corticosteroid effects cannot be assessed unless exposed and non-exposed patients are categorically separated. Thus, proposing that this single-center, observational study "has relevance for clinical practice", a conclusion unsupported by data, will likely mislead and confound many bedside physicians. Undoubtedly, the most likely explanation for Yehya et al.'s findings are (1) selection of steroid therapy for the sickest patients (confounding by indication) and (2) rebound effects resulting from abrupt discontinuation of corticosteroids, as is well documented by worsening $\mathrm{PaO}_{2} / \mathrm{FiO}_{2}$ ratios and increasing CRP levels.

Owing to the wide-ranging implications and inherent responsibility of publishing patient data, it is imperative that we treat this topic with the utmost equipoise until clear evidence for or against steroid use in ARDS/ PARDS is gained. Whether comparative effectiveness research (CER) can provide such evidence is questionable, since the US Food and Drug Administration, European Medicines Agency, or other labeling agencies do not consider this research methodology Level 1 evidence. CER studies can "adjust" the outcomes for measured confounders, and bootstrapping techniques like propensity scoring can reduce the margin of inferential errors, but only large, welldesigned RCTs can control for unmeasured and non-measurable confounders. We recommend caution in drawing conclusions from a data set with multiple confounding variables and improper controls. Statistical approaches such as propensity score matching can only take into account measured confounding factors, whereas randomized trials allow for controlling of both measured and unmeasured confounders. The beneficial or no-harm results reported in adult RCTs cannot be disregarded unless systematically investigated in pediatric patients. We recently published a feasibility RCT investigating prolonged low-dose methylprednisolone in pediatric ARDS [5] and, undoubtedly, there is an urgent need to conduct a large-scale, well-designed RCT in PARDS.

\section{References}

1. Yehya N, Servaes S, Thomas NJ, Nadkarni VM, Srinivasan V (2015) Corticosteroid exposure in pediatric acute respiratory distress syndrome. Intensive Care Med. doi: 10.1007/s00134-015-3953-4

2. Peters MJ, Ray S, Kneyber M (2015) Corticosteroids for paediatric ARDS: unjustified-even unjustifiable? Intensive Care Med. doi: 10.1007/s00134-015-3963-2

3. Confalonieri M, Urbino R, Potena A, Piattella M, Parigi P, Puccio G, Della Porta R, Giorgio C, Blasi F, Umberger R, Meduri GU (2005) Hydrocortisone infusion for severe community-acquired pneumonia: a preliminary randomized study. Am J Respir Crit Care Med 171:242-248 
4. Meduri GU, Annane D, Chrousos GP, Marik PE, Sinclair SE (2009) Activation and regulation of systemic inflammation in ARDS: rationale for prolonged glucocorticoid therapy. Chest 136:1631-1643
5. Drago BB, Kimura D, Rovnaghi CR, Schwingshackl A, Rayburn M, Meduri GU, Anand KJ (2015) Double-blind, placebo-controlled pilot randomized trial of methylprednisolone infusion in pediatric acute respiratory distress syndrome. Pediatr Crit Care Med 16:e74-e81
A. Schwingshackl (®) - G. U. Meduri •

D. Kimura - S. A. Cormier - K. J. S. Anand Department of Pediatrics, University of California Los Angeles David Geffen School of Medicine, 10833 Le Conte Ave, Los Angeles, CA 90095, USA

e-mail: aschwingshackl@gmail.com 